УДК 581.1:633.358

\title{
АНТИОКСИДАНТНЫЕ СВОЙСТВА ФЕНОЛСОДЕРЖАЩИХ ЭКСТРАКТОВ ИЗ ВАКУОЛЯРНОГО СОКА СТОЛОВОЙ СВЕКЛЫ (ВЕTA VULGARIS L.) ПОСЛЕ КИСЛОТНОГО ГИДРОЛИЗА
}

\author{
() Н.В. Озолина", Л.Е. Макарова, А.Н. Возненко, Е.В. Колесникова, Л.В. Дударева \\ Сибирский институт фризиологии и биохимии растений СО РАН, \\ ул. Лермонтова, 132, Иркутск, 664033 (Россия), e-mail: ozol@sifibr.irk.ru, \\ makarova@sifibr.irk.ru
}

После кислотного гидролиза вакуолярного сока корнеплодов столовой свеклы (Beta vulgaris L.) при помощи

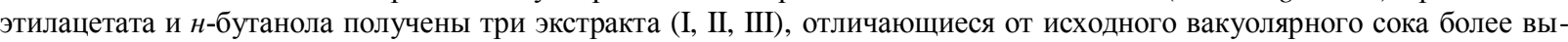
соким содержанием фенольных компонентов. Экстракты различались по содержанию и составу фенольных соединений (ФС), аминокислот, антиоксидантной активности. Экстракт I, в сравнении с экстрактами II и III, имел максимальные показатели антиоксидантной активности, содержания и числа ФС, но минимальное содержание аминокислот. Этот экстракт может быть эффективен в качестве активной добавки в продукты переработки растительного сырья для снижения окислительных процессов.

Ключевые слова: Beta vulgaris (L.), вакуолярный сок, фенольные соединения, аминокислоты, антиоксидантная активность.

\section{Введение}

Фенольные соединения (ФС) - вторичные метаболиты растений, включающих весьма обширную группу разнообразных по химической структуре веществ. Многие из фенольных соединений обладают ярко выраженной биологической активностью, которая в какой-то мере обусловлена их участием в регуляции окислительных процессов $[1,2]$. При этом данные вещества способны к прямому ингибированию свободнорадикальных процессов [3] и хелатированию металлов, включая железо, медь [4-6], однако в определенных условиях они могут участвовать в генерации активных форм кислорода и действовать как прооксиданты [7].

Большое внимание в настоящее время уделяется изучению антиоксидантной активности веществ растительного происхождения, которые находят широкое применение в официальной и народной медицине, в косметике и пищевой промышленности. Среди соединений антиоксидантного действия наиболее перспективными являются комплексы природных полифенолов, которые входят в состав растительных продуктов, традиционно употребляемых человеком в пищу и являются эволюционно-адаптированными для человеческого организма. Во многих случаях в экстрактах растений обнаружена высокая антиоксидантная

Озолина Наталья Владимировна - заведующая лабораторией физиологии растительной клетки, e-mail: ozol@ sifibr.irk.ru

Макарова Людмила Евгеньевна - и.о. заведующей. лабораторией устойчивости растений,

e-mail: makarova@ sifibr.irk.ru

Возненко Анастасия Николаевна - студент

Колесникова Екатерина Владимировна - младший научный сотрудник, кандидат биологических наук Дударева Любовь Виссарионовна - заведующая лабораторией физических методов исследования активность, и предполагается, что эта активность может вносить существенный вклад в лечебный эффект [8, 9].

Столовая свекла активно используется не только в питании, но и в профилактике болезней с целью повышения иммунитета, для нормализации обменных процессов, как онкопротектор и т.д. [10]. Значительную роль в эффективности положительного воздействия свеклы играют особенности состава фенольных соединений вакуолярного сока, который

\footnotetext{
*Автор, с которым следует вести переписку.
} 
в настоящее время изучен недостаточно. В ряде работ приведены данные по составу фенольных соединений корнеплодов столовой свеклы [11, 12], много исследований посвящено изучению бетацианинов, их выделению, исследованию их свойств $[13,14]$. Изучение антиоксидантной активности вакуолярного сока в экстрактах, различающихся по своим биохимическим свойствам, практически не проводилось. Вакуолярный сок может содержать значительное количество фенольных соединений, в том числе и обладающих высокой антиоксидантной активностью. Часть этих соединений может находиться в связанном состоянии. Поэтому для выяснения всего потенциала антиоксидантной активности фенольных соединений вакуолярного сока необходимо перед фракционированием вакуолярного сока провести гидролиз. Целью нашей работы была сравнительная оценка свойств трех фенолсодержащих экстрактов из вакуолярного сока корнеплодов столовой свеклы, подвергнутого кислотному гидролизу, и выявление фракции с повышенным содержанием антиоксидантных соединений для их использования в качестве пищевых добавок для снижения окислительных процессов в продуктах переработки растительного сырья.

\section{Экспериментальная часть}

Получение вакуолярного сока. Вакуолярный сок получали из фракции изолированных вакуолей, выделенных по методу [15]. Фракцию изолированных вакуолей выделяли из корнеплодов столовой свеклы (Beta vulgaris L.) сорта Бордо, находящихся в стадии покоя.

Кислотный гидролиз вакуолярного сока и получение экстрактов ФС. ФС экстрагировали из вакуолярного сока, подвергнутого гидролизу 2 н $\mathrm{HCl}$ в течение 1 ч на водяной бане при 90-95 ${ }^{\circ} \mathrm{C}$. После доведения до $\mathrm{pH} 3,0-4,0$ при помощи 2 н $\mathrm{NaOH}$ ФС из гидролизата извлекали в два этапа, вначале этилацетатом, затем $н$-бутанолом.

Фенольные соединения, извлекаемые этилацетатом, вошли в два экстракта, обозначенных нами как «экстракт I» и «экстракт II». В экстракте I оказались ФС, которые извлекли из этилацетата в 5\%-ный водный раствор $\mathrm{NaHCO}_{3}$, затем из содового раствора, подкисленого при помощи 4 н $\mathrm{HCl}$ до рH 3,0-4,0, еще раз экстрагировали этилацетатом. Неперешедшая из этилацетата в раствор $\mathrm{NaHCO}_{3}$ группа ФС оказалась в экстракте II. Из полученных вышеописанным образом этилацетатных экстрактов удаляли этилацетат путем упаривания его в токе холодного воздуха и остатки перерастворяли в небольших объемах $96 \%$-ного этанола. Экстракт III, полученный при использовании $\mu$-бутанола в качестве экстрагента, также упаривали в токе холодного воздуха, удалив из него $н$-бутанол, и остаток перерастворяли в 96\%-ном этаноле.

Содержание ФС в экстрактах устанавливали с реактивом Фолина-Дениса [16]. Для построения калибровочной кривой, применявшейся при количественных расчетах, использовали коммерческий препарат (-)-эпикатехин (ICN Biomedical Inc, Канада).

Анализ состава ФС в экстрактах. Состав ФС в экстрактах изучали с применением методов хроматографии на бумаге (БХ), ТСХ, ВЭЖХ, по показателям УФ-спектроскопии, цветных реакций с реагентами на фенольные соединения по [17].

Исследования спектров поглощения в области 200-500 нм у элюированных с необработанных реагентами хроматограмм (бумажная и тонкослойная хроматография) веществ осуществляли на спектрофотометре Specord S100 «Analytik Jena» (Германия).

Для БХ использовали Watman 1CHR «Sigma-Aldrich», (Германия), для TCX - пластинки «Sorbfi» размером 100×100 мм (Россия). ФС экстрактов подвергали двумерному разделению на бумаге, используя в первом направлении 5\%-ную уксусную кислоту, затем систему н-бутанол - уксусная кислота - вода (Б:У:В, $4: 1: 2, \mathrm{v} / \mathrm{v})$.

ТСХ применяли для выявления фенольных компонентов, проявляющих активность в свободнорадикальных реакциях: анти- и прооксиданты. Для деления в ТС в первом направлении применяли систему толуол - 1,4-диоксан - уксусная кислота (Т:Д:У, $90: 25$ :4, v/v), во втором - хлороформ - этанол (4 : 1, v/v).

Анализ состава фенольных соединений методом ВЭЖХ осуществляли на хроматографе с УФдетектором «Shimadzu» LC-10ATvp, (Япония). Адсорбционные профили получали при 280 нм. Разделение содержавшихся в экстрактах фенольных компонентов проводили на обращено-фазовой колонке Реrfect Bond ODS-H, химическая модификация $\mathrm{C}_{18}(250 \times 4,6$ мм), 5 мкм, в градиенте концентрации А:Б от 30 до 90\% в течение 60 мин. При этом применяли два варианта систем растворителей, различавшихся по компоненту Б. В обоих вариантах раствор А - ацетонитрил, Б в варианте 1 представлял 0,1 M перхлорат Li 
с 0,1\%-ной трифторуксусной кислоты, $\mathrm{pH} 4,0$, а в варианте 2 это был 0,01\%-ный водный раствор трифторуксусной кислоты, $\mathrm{pH} 4,0$. Для идентификации соединений описываемым методом использовали показатели времени удерживания в адсорбционных профилях исследуемых экстрактов, которые сравнивали по изменению интенсивности пиков до и после внесения в экстракты метчиков (метод добавок), и изучали УФ-спектры, которые получали в остановленном потоке элюента.

Для идентификации присутствовавших в экстрактах веществ использовали хроматографические и спектроскопические показатели для аутентичных образцов ФС, приобретенных в фирмах: «Sigma» (Швеция), «ICN Biomedical Inc» (Канада), «Fluka AG» (Швеция), «Serva» (США).

Определение антиоксидантной активности фенолсодержащих экстрактов. Активность в ингибировании свободнорадикальных реакций фенолсодержащих экстрактов определяли с использованием 1,1дифенил-2-пикрилгидразила (ДФПГ), составляя реакционные смеси по прописи из работы [18]. Для сравнения активности изучаемых экстрактов использовали принцип и формулу для расчетов, примененных авторами работы [19]. Пробная смесь для анализа содержала 0,2 мл экстракта при концентрации в нем сухих веществ 200 мкг/мл, 2,0 мл 0,1 мМ раствора ДФПГ«Sigma-Aldrich» (США), 0,8 мл 40\%-ного этанола. Концентрация вносимых в реакционную смесь сухих веществ экстрактов была оптимизирована по калибровочному графику для катехина. В качестве «пустой пробы» была смесь, содержащая 2,0 мл 0,1 мМ раствора ДФПГ + 1,0 мл 40\%-ного этанола. Смеси инкубировали в течение 15 мин в темноте при комнатной температуре и измеряли оптическую плотность при 517 нм на спектрофотометре Specord S100 против смеси из 0,2 мл экстракта и 2,8 мл 40\%-ного этанола, служившей в качестве контрольного образца.

Антиоксидантную активность для веществ, внесенных в указанные выше среды, рассчитывали по формуле

$$
\text { ингибирование }(\%)=[(\mathrm{AB}-\mathrm{AA}) / \mathrm{AB}] \times 100 \text {, }
$$

где $\mathrm{A}_{\mathrm{A}}$ - абсорбция определяемого экстракта через 15 мин инкубации; $\mathrm{A}_{\mathrm{B}}$ - абсорбция пустой пробы (без экстракта).

Выявления фенольных анти- и прооксидантов хроматографическим методом. Фенолсодержащие экстракты наносили на пластинки «Sorbfil» (Россия) и проводили разделение компонентов двумерно. В первом направлении использовали систему Т:Д:У (90:25:4, v/v), во втором - хлороформ - этанол (4 : 1, v/v). Присутствие на ТСХ фенольных анти- и прооксидантов устанавливали по степени обесцвечивания $\beta$ - каротина [20]. Наличие фенольных соединений в областях реагирования доказывали, используя необработанные $\beta$-каротином хроматограммы с теми же экстрактами. При этом часть хроматограмм опрыскивали реагентами на фенольные соединения, с другой части хроматограмм пятна элюировали в 96\%-ный этанол и присутствующие в растворе вещества изучали методами ВЭЖХ-анализа, который включал сопоставление времени удерживания с метчиками (метод добавок) и получение УФ-спектров в остановленном потоке.

Определение количества и состава аминокислот во фракциях. Анализ аминокислот осуществляли на анализаторе AAA T-339 (Чехия) в Li-цикле по методике, описанной в работе [21], и проводили в экстрактах после их гидролиза 6 н $\mathrm{HCl}$ при $110{ }^{\circ} \mathrm{C}$ в течение 24 ч.

Статистическая обработка данных. Все эксперименты проводили в 3-кратных биологических и 3-5кратных аналитических повторностях (n=3-5). Результаты количественных определений были обработаны статистически: рассчитаны средние арифметические значения и их стандартные отклонения [22]. Достоверность различий анализировали по критерию Стьюдента. Для расчетов применяли программу MExcell.

\section{Обсуждение результатов}

Двуступенчатая экстракция веществ из водной среды, с применением вначале этилацетата, затем н-бутанола, позволяет отделить липофильные компоненты от водорастворимых, которые попадают в разные экстракты. Характерно, что до гидролиза около 60\% фенольных соединений от их общего содержания в вакуолярном соке входили в состав компонентов, экстрагируемых этилацетатом. Разрыв эфирных связей между фенольными и нефенольными соединениями (углеводами, аминокислотами, оксикарбоновыми кислотами и др.) в результате гидролиза способствовал увеличению количества фенольных веществ, экстрагируемых этилацетатом, до 77\% от их общего содержания во фракциях. Таким образом, возрастало количество веществ повышенной липофильности. 
Общее количество ФС, извлеченных из в вакуолярного сока после гидролиза кислотой, составляло немного более $1,2 \%$ от массы сухих веществ, присутствующих в соке. В полученных экстрактах процентное содержание ФС от массы сухих веществ выше: в экстракте I ФС составляли 7,2 $\pm 0,09 \%$, в экстракте II $6,7 \pm 0,34 \%$ и в экстракте III - 3,78 $\pm 0,04 \%$.

В составе экстрактов наряду с фенольными компонентами выявлены аминокислоты. Наибольшее количество аминокислот обнаружено в экстракте III, где они составляли 0,55\% от сухих веществ вакуолярного сока. В экстрактах I и II этот показатель составлял, соответственно, 0,02 и 0,04. При этом состав аминокислот в экстрактах не был сходным. Так, в экстракте I найдены аспарагиновая и глутаминовая кислоты, аланин, глицин, серин, треонин. В экстракте II наряду с первыми присутствовали изолейцин и лейцин. В обоих экстрактах среди аминокислот отмечено значительное преобладание глицина. Наиболее богат аминокислотами был экстракт III. В нем кроме всех вышеперечисленных аминокислот были обнаружены аргинин, валин, гистидин, тирозин, фенилаланин и гамма-аминомасляная кислота. В данном экстракте по массе существенно доминировала глутаминовая кислота и отмечено высокое содержание валина, изолейцина и лейцина.

Состав остальных веществ, представляющих основную массу в экстрактах из гидролиза вакуолярного сока, пока не исследован.

ВЭЖХ-хроматограммы на рисунке 1 позволяют заметить наибольшее разнообразие фенольных компонентов в составе экстрактов I и II, значительно меньшее число этих веществ в экстракте III. Аналогичного характера различия по компонентному составу у экстрактов установлены методами хроматографии на бумаге.

Данные ВЭЖХ-анализа по УФ-спектрам в остановленном потоке и проведенные методом добавок (см. Методику), свидетельствуют о присутствии в составе экстрактов I и II ряда одинаковых компонентов. В их числе апигенин, кверцетин, кемпферол и несколько неидентифицированных нами соединений. Примером таких неидентифицированных компонентов являются вещества, условно обозначенные нами С1 и С2 (рис. 1), которые, как это будет показано ниже, оказались в группе антиоксидантов. В обоих экстрактах данные вещества входят в число мажорных компонентов. В таблице приведены хроматографические характеристики обоих веществ. Одинаковыми оказались УФ-спектры этих компонентов (на рисунке 2 представлен УФ-спектр С1, растворенного в 96\%-ном этаноле).

У полученных нами экстрактов обнаружена разная антиоксидантная активность (рис. 3), которая определялась методом с применением ДФПГ. Более высоким показателем этой активности отличался экстракт I, немного меньшим - экстракт III. Самая низкая активность у компонентов вакуолярного сока и у экстракта II. Очевидно, кислотный гидролиз способствовал появлению в гидролизате высокоактивных компонентов, которые определили более высокую эффективность экстрактов I и III в ингибировании свободнорадикальных процессов. В числе активных веществ могут быть не только ФС, но и аминокислоты, которые также являются эффективными природными антиоксидантами [23].

Путем двумерного разделения компонентов экстракта I методом тонкослойной хроматографии на хроматограмме обнаружено три зоны активности в отношении окисления $\beta$-каротина: две из них содержали вещества, ингибирующие его окисление (антиоксиданты), одна - ускоряющая данный процесс (прооксидант). В экстрактах II и III на хроматограммах выявлено по одной зоне с антиоксидантной активностью, а зоны с прооксидантной активностью отсутствовали. Следует отметить, что этим методом не выявлена антиоксидантная активность у веществ вакуолярного сока. По-видимому, гидролиз способствовал появлению высокоактивных компонентов, влияющих на окисление $\beta$-каротина.

Наиболее высокие показатели антиоксидантной активности и содержания ФС явились основанием для более детального изучения состава фенольных компонентов экстракта I и выявления среди них соединений, участвующих в свободнорадикальных реакциях. Для исследования указанного экстракта были использованы дополнительных методы, результаты которых представлены ниже. Так, методами ВЭЖХанализа, хроматографии на бумаге с проведением качественных реакций с реагентами на ФС было установлено присутствие соединений фенольной природы в зонах, проявивших активность в свободнорадикальных реакциях. 

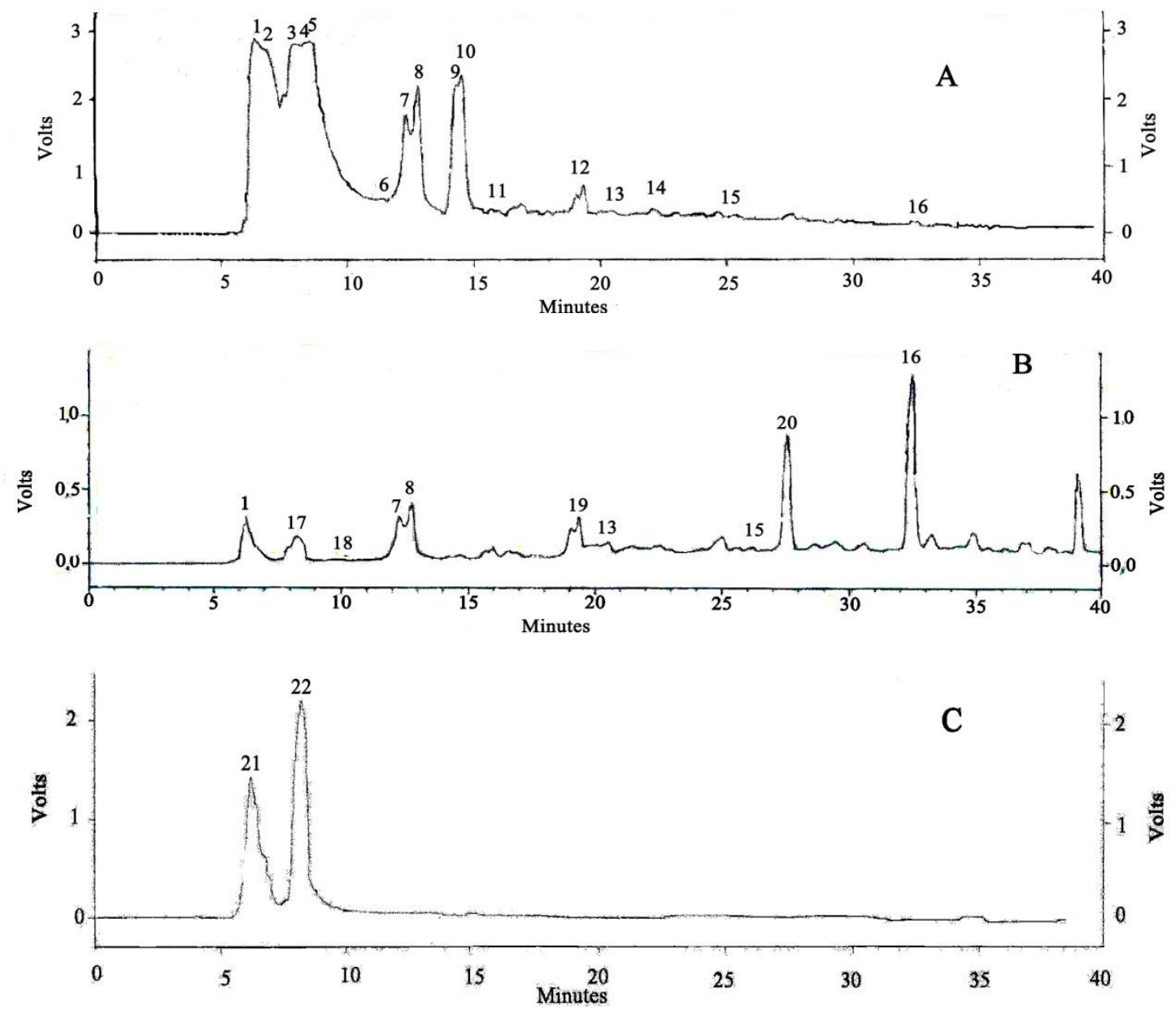

Рис. 1. ВЭЖХ-хроматограммы для экстрактов, полученные при разделении в системе ацетонитрил:0,1 М перхлорат Li c 0,1\% трифторуксусной кислоты. A, B, C - соответственно, экстракты I, II, III. Обозначения пиков для соединений, содержавшихся в экстрактах: 1 - неидентифицированное соединение;

2 - неидентифицированное соединение с $\lambda_{\max }=286$ нм; 3 - неидентифицированное соединение

с $\lambda_{\max }=283$, (290) нм; 4 - хлорогеновая кислота*; 5 - протокатеховая кислота*; 6 - ванилиновая кислота*; 7 - вещество С1 с $\lambda_{\max }=292$ нм; 8 - вещество С 2 с $\lambda_{\max }=292$ нм; 9 - неидентифицированное соединение с $\lambda_{\max }=268$ нм; 10- п-кумаровая кислота*; 11 - феруловая кислота*; 12 - апигенин*; 13 - кверцетин*; 14 - салициловая кислота*; 15 - кемпферол*; 16 - неидентифицированное соединение с $\lambda_{\max }=272,(290)$ нм; 17 - неидентифицированное соединение с $\lambda_{\max }=282$ нм; 18 - эпикатехин $*$; 19 - апигенин*; 20 - неидентифицированное соединение с $\lambda_{\max }=268$ нм; 21 - неидентифицированное соединение с $\lambda_{\max }=284$ нм; $22-$ неидентифицированное соединение с $\lambda_{\max }=285$ нм.

Примечание: * - соединения, присутствие которых подтверждено путем внесения в экстракт соответствующих аутентичных образцов - метчиков (метод «добавок», см. Методику).

Хроматографические показатели веществ C1 и C2, обнаруженных в экстрактах I и II

\begin{tabular}{|c|c|c|c|c|c|c|c|c|c|c|}
\hline \multirow[b]{2}{*}{ 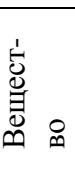 } & \multirow[b]{2}{*}{$\begin{array}{c}\text { Видимый } \\
\text { свет }\end{array}$} & \multirow[b]{2}{*}{ УФ-свет } & \multirow[b]{2}{*}{$\begin{array}{c}\text { Видимый } \\
\text { свет (после } \\
\text { УФ-света) }\end{array}$} & \multicolumn{3}{|c|}{ Обработка реагентами } & \multicolumn{3}{|c|}{$R_{f}$} & \multirow[b]{2}{*}{$\begin{array}{l}\mathrm{t}_{\text {уд. }}, \\
\text { мин }\end{array}$} \\
\hline & & & & $\begin{array}{c}\text { ДПНА } \\
+ \\
\mathrm{Na}_{2} \mathrm{CO}_{3} \\
\end{array}$ & $\begin{array}{c}\text { ДСК } \\
+ \\
\mathrm{Na}_{2} \mathrm{CO}_{3} \\
\end{array}$ & $\mathrm{FeCl}_{3}$ & $\begin{array}{c}5 \% \text {-ная } \\
\text { уксусная } \\
\text { кислота }\end{array}$ & БУВ & тДУ & \\
\hline $\mathrm{C} 1$ & Б/цв. & Темн & Б/цв. & Сер.-ж. & Св.ж. & Cep. & 0,85 & 0,93 & 0,85 & $\begin{array}{c}12,317 * \\
25,533 * *\end{array}$ \\
\hline $\mathrm{C} 2$ & Б/цв. & Гол. & Св.ж. & Ж.-оранж. & Св.ж. & Cep. & 0,77 & 0,92 & 0,84 & $\begin{array}{c}12,775^{*} \\
26,467 * *\end{array}$ \\
\hline
\end{tabular}

Сокращения: ДСК, ДПНА - диазотированные сульфаниловая кислота и пара-нитроанилин; б/цв. - бесцветный; св. светлый; темн. - темный; гол. - голубой; ж. - желтый; оранж. - оранжевый; сер. - серый. * и ** указано время удерживания $\left(\mathrm{t}_{\mathrm{y}}\right)$ при разделении методом ВЭЖХ, соответственно, в системах ацетонитрил: $0,1 \mathrm{M}$ перхлорат Li c $0,1 \%$ трифторуксусной кислоты и ацетонитрил: 0,1\%-ная трифторуксусная кислота. 


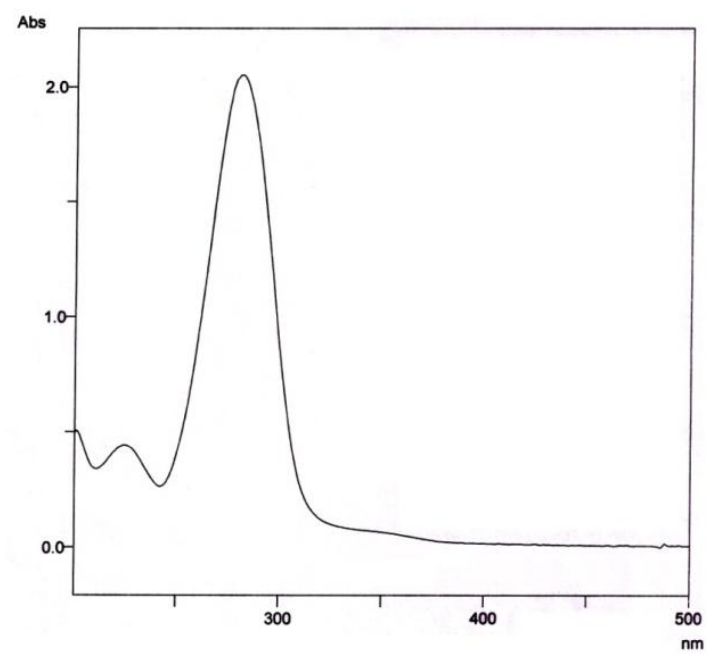

Рис. 2. УФ-спектр вещества С1 в 96\%-ном этаноле, получен на спектрофотометре S-100

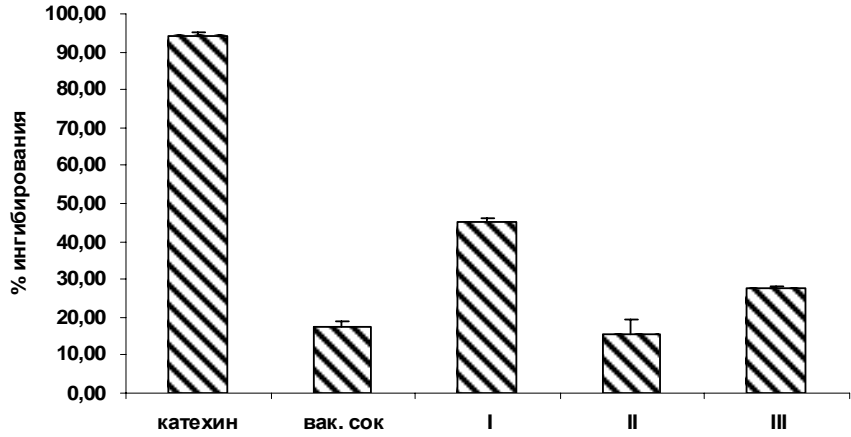

Рис. 3. Антиоксидантная активность катехина, вакуолярного сока и экстрактов из него, полученных после кислотного гидролиза: вак. сок - вакуолярный сок; I, II, III - обозначения экстрактов. \% ингибирования - антиоксидантная активность исследуемого образца относительно контроля (контроль - реакционная среда с ДФПГ без экстракта)

Для изучения состава веществ, присутствовавших в активных зонах, их элюировали в 96\%-ный этанол с параллельных ТСХ, которые не подвергались обработке реагентами. В результате установлено, что в одной из зон антиоксидантной активности, с $\mathrm{R}_{\mathrm{f}} 0,0-0,1$ в первом направлении и $0,0-0,63$ - во втором направлении (соответственно, в системах Т:Д:У и хлороформ - этанол, см. Методику), присутствовало 7 компонентов с максимумами поглощения в области 260-280 нм, относящихся к числу характерных для ароматических веществ. В другой зоне с аналогичной активностью, с показателями $\mathrm{R}_{\mathrm{f}}$ близкими к 1,0 (в обеих системах), вместе с 15 компонентами с различными максимумами поглощения, входящими в область 260-290 нм, обнаружены выше названные вещества С1 и С2. Их присутствие нами доказано по спектрам поглощения в остановленном потоке (ВЭЖХ-анализ) и методами бумажной хроматографии, с использованием реагентов на фенольные соединения. Присущее этим веществам серое окрашивание с хлорным железом (табл.) может свидетельствовать о наличии у них вицинальных ОН-групп [17], которые, как известно, способствуют проявлению высокой антиоксидантной активности у ароматических соединений [24].

Довольно обширная по площади на ТСX зона прооксидантной активности, обнаруженная по быстрому обесцвечиванию $\beta$-каротина, приходилась на область хроматограммы с $\mathrm{R}_{\mathrm{f}} 0,28-0,66$ и $0,69-0,84$, соответственно, в 1-м и 2-м направлениях. На ВЭЖХ-хроматограмме для элюента из обсуждаемой зоны TCX, среди 13 пиков 6 имели отношение к компонентам с различными максимумами поглощения в области 250-310 нм. Более детальные исследования состава компонентов этой зоны не проводилось. Необъяснимо пока, как присутствие в экстракте I компонентов, способных вызвать быстрое окисление $\beta$-каротина, сказывается на общем эффекте ингибирования свободнорадикальных реакций, определенного при помощи ДФПГ, который у данного экстракта оказался наиболее сильным, если сравнивать его с двумя другими экстрактами и вакуолярным соком (рис. 3).

Низкие, по сравнению с катехином, показатели антиоксидантной активности для вакуолярного сока и экстрактов из него, установленные при помощи ДФПГ, обусловлены невысоким содержанием ФС в общей массе их сухих веществ (см. выше). Антиоксидантная активность не подверженного гидролизу вакуолярного сока, надо полагать, в основном проявляется за счет присутствующих в нем беталаинов [19, 24, 25]. Фенольные же соединения, по результатам наших предварительных анализов и по данным литературы [26], преимущественно входят в состав неактивных конъюгатов, из состава которых в наших экспериментах они высвобождались вследствие кислотного гидролиза.

Экстракты I и II содержали практически одинаковое количество ФС и не очень сильно отличались по содержанию аминокислот, но существенно различались по антиоксидантным свойствам. Это обстоятельство позволяет высказать предположение о зависимости антиоксидантной активности экстрактов от состава (разнообразия) присутствующих в них ФС. Поэтому наибольший эффект ингибирования окислительных процессов у экстракта I можно объяснить не столько содержанием, сколько разнообразием пред- 
ставленных в нем фенольных соединений (рис. 1), а также присутствием среди них особенно активных в свободнорадикальных реакциях компонентов. На последнее указывают приведенные выше данные по их участию в обесцвечивании $\beta$-каротина.

Интересно отметить, что в экстракте III содержание фенольных соединений почти в два раза меньшем, чем в экстракте II, но его актиоксидантная активность существенно выше. Этот факт можно объяснить более высоким содержанием в экстракте III аминокислот. Она выше в 27 и 14 раз, соответственно, по сравнению с экстрактами I и II. Их состав более разнообразен. В частности, среди них выявлены и ароматические аминокислоты - тирозин и фенилаланин, которые также активно могут участвовать в свободнорадикальных реакциях как перехватчики свободных радикалов [24]. Вероятно, более высокий антиоксидантный эффект компонентов экстракта III является следствием аддитивного действия фенольных компонентов и аминокислот.

\section{Выводы}

Таким образом, в наших экспериментах максимальное содержание ФС и антиоксидантная активность оказалась у экстракта I, полученного по схеме экстракции: этилацетат $\rightarrow 5 \% \mathrm{NaHCO}_{3} \rightarrow$ этилацетат. Присутствие ФС в зонах анти- и прооксидантной активности, установленных после разделения компонентов экстракта на ТСХ, позволяет предположить участие этих веществ в ингибировании и стимулировании окисления $\beta$-каротина. Таким образом, роль ФС в полученных нами экстрактах может быть двоякой, но их активность в свободнорадикальных процессах несомненна. Результаты проведенных исследований позволили подтвердить участие присутствующих в экстрактах фенольных соединений в свободнорадикальных реакциях и отработать способ получения экстрактов вакуолярного сока, обладающих наибольшей антиоксидантной активностью с целью их использования в качестве биологически активных добавок для снижения окислительных процессов в продуктах переработки растительного сырья.

Авторы выражают признательность инженерам группь физических методов исследования СИФИБР СО РАН И.Г. Петровой и А.М. Собенину за техническую помощь при выполнении экспериментов.

\section{Список литературы}

1. Максимов О.Б., Ребачук Н.М., Богуславская Л.Б. Скрининг для обнаружения антиоксидантной активности в экстрактах из растений // Растительные ресурсы. 1985. Т. 21, № 2. С. 216-220.

2. Masaki H. Active-oxygen scavenging activity of plant extracts // Biol. Pharm. Bull. 1995. Vol. 18. Pp. 162-166.

3. Rice-Evans C.A., Miller N.J., Bolwell P.G., Bramley P.M., Pridh J.B. The relative antioxidant activities of plantderived polyphenolics flavonoids // Free Radical Res. 1995. Vol. 22. Pp. 375-383.

4. Afanas'ev I.B., Dorozhko A.I., Brodskii A.V., Kostyuk V.A., Potapovitch A.I. Chelating and free scavenging mechanisms of inhibitory action of rutin and quercetin in lipid peroxidaton // Z. Biochem. Pharmacol. 1989. Vol. 38. Pp. 1763-1769.

5. Melidou M., Riganakos K., Galaris D. Protection against nuclear DNA dam age offered by flavonoids in cells exposed to hydrogen peroxide: the role of iron chelation // Free Radic. Biol. Med. 2005. Vol. 39. Pp. 1591-1600.

6. Hoshino N., Kimura T., Yamaji A., Ando T. Damage to the cytoplasmic membrane of Escherichia coli by catechincopper(II) complexes // Free Radic. Biol. Med. 1999. Vol. 27. Pp. 1245-1250.

7. Smith A.H., Imlay J.A., Mackie R.I. Increasing oxidative stress response allows Escherichia coli to overcome inhibitory effect of condensed tannins // Appl. Environ. Microbiol. 2003. Vol. 69. Pp. 3406-3411.

8. Kahkonen M., Hopia A.I., Vuorela H.J., Rauha J.P., Pihlaja K., Kuiaia T.S., Heinonen M. Antioxidant activity of plant extracts containing phenolic compounds // J. Agric. Food Chem. 1999. Vol. 47(10). Pp. 3954-3962.

9. Ghasemzadeh A., Jaafar H., Rahmat A. Antioxidant activities, total phenolics and flavonoids content in two varieties of Malaysia young ginger (Zinger officinale Roscoe) // Molecules. 2010. Vol. 15. Pp. 4324-4333.

10. Strack D., Vogt T., Schliemann W. Recent advances in betalain research // Phytochemistry. 2003. Vol. 62. Pp. 247-269.

11. Kujala T.S., Loponen J.M., Klika K.D., Pihlaja K. Phenolics and betacyanins in red beet root (Beta vulgaris): distribution and effect of cold storage on the content of total phenolics and three individual compounds // J. Agric. Food Chem. 2000. Vol. 48(11). Pp. 5338-5342.

12. Kujala T.S.,Vienola M.S., Klika K.D., Loponen J.M., Pihlaja K. Betalain and phenolic compositions of four beetroot (Beta vulgaris) cultivars // Eur Food Technol. 2002. Vol. 214. Pp. 505-510.

13. Akita T., Hina Y., Nishi T. New medium composition for high betacyanin production by a cell suspension culture of table beet (Beta vulgaris L.) // Biosci. Biotechnol. Biochem. 2002. Vol. 66(4). Pp. 902-905. 
14. Georgiev V.G., Weber J, Kneschke E-M., Denev P.N., Bley T., Pavlov A.I. Antioxidant Activity and Phenolic Content of Betalain Extracts from Intact Plants and Hairy Root Cultures of the Red Beetroot Beta vulgaris cv. Detroit Dark Red // Plant Foods Hum Nutr. 2010. Vol. 65. Pp. 105-111.

15. Саляев Р.К., Кузеванов В.Я., Хаптагаев С.Б., Копытчук В.Н. Выделение и очистка вакуолей и вакуолярных мембран из клеток растений // Физиология растений. 1981. Т. 28. С. 1295-1305.

16. Запрометов М.Н. Основы биохимии фенольных соединений. М., 1974. 214 с.

17. Прохазка Ж. Фенолы и ароматические кислоты // Хроматография на бумаге / под ред. И.М. Хайса, К. Мацека. М., 1962. C. 301-333.

18. Georgiev V.G., Weber J, Kneschke E-M., Denev P.N., Bley T., Pavlov A.I. Antioxidant activity and phenolic content of betalain extracts from intact plants and hairy root cultures of the red beetroot Beta vulgaris cv. Detroit dark red // Plant Foods Hum Nutr. 2010. Vol. 65. N 2. Pp. 105-111.

19. Pavlov A., Kovatcheva P., Georgiev V., Koleva I., Ilieva M. Biosynthesis and radical scavenging activity of betalains during the cultivation of red beet (Beta vulgaris) hairy root cultures // Z. Naturforsch C. 2002. Vol. 57. N 7/8. Pp. 640-644.

20. Максимов О.Б., Ребачук Н.М., Богуславская Л.Б. Скрининг для обнаружения антиоксидантной активности в экстрактах из растений // Растительные ресурсы. 1985. Т. 21. № 2. С. 216-220.

21. Козаренко Т.Д. Ионообменная хроматография аминокислот. Новосибирск, 1975. с. 133.

22. Лакин Г.Ф. Биометрия. М., 1990. 352 с.

23. Штаркман И.Н., Гудков С.В., Черников А.В., Брусков В.И. Влияние аминокислот на образование перекиси водорода и гидроксильных радикалов в воде и 8-оксогуанина в ДНК при воздействии рентгеновского излучения // Биохимия. 2008. Т. 73. № 4. С. 576-586.

24. Аверьянов А.А., Лапикова В.П. Генерация кислородных радикалов фенольными соединениями в связи с иммунитетом растений // Кислородные радикалы в химии, биологии и медицине. Рига, 1988. С. 203-222.

25. Gandia-Ferrero F., Escribano J., Garcia-Carmona F. Structural implications on color, fluorescence, and antiradical activity in betalains // Planta. 2010. Vol. 232. N 2. Pp. 449-460.

26. Pedreno M.A., Escribano J. Correlation between antiradical activity and stability of betanine from Beta vulgaris L. roots under different pH, temperature and light conditions // J. Sci. Food Agric. 2001. Vol. 81. N 7. Pp. 627-631.

27. Kujala T.S., Loponen J.M., Klika K.D., Pihlaja K. Phenolics and betacyanins in red beetroot (Beta vulgaris) root: distribution and effect of cold storage on the content of total phenolics and three individual compounds // J.Agric.Food. Chem. 2001. Vol. 48. N 11. Pp. 5338-5342. 
Ozolina N.V., Makarova L.E., Voznenko A.N., Kolesnikova E.V., Dudareva L.V. ANTIOXIDANT PROPERTIES PHENOLIC EXTRACTS FROM JUICE VACUOLAR BEETROOT (BETA VULGARIS L.) AFTER ACID HYDROLYSIS

Siberian Institute of Plant Physiology and Biochemistry SB RAS, Lermontova st., 132, Irkutsk, 664033 (Russia), e-mail:ozol@sifibr.irk.ru,makarova@sifibr.irk.ru

After acid hydrolysis the vacuolar roots of red beet juice (Beta vulgaris L.) using ethyl acetate and n-butanol extract obtained three (I, II, III), which differ from the original juice vacuolar higher content of phenolic components. Extracts differed in content and composition of phenolic compounds (FS), amino acids, antioxidant activity. Extract I, in comparison with the extracts II and III had maximum values of the antioxidant activity, and the content of the FS number, but the minimum amino acid content. This extract may be effective as a additives in products of agrotechny of vegetable raw materials to reduce oxidative processes.

Keywords: Beta vulgaris (L.), vacuolar sap, phenolic compounds, amino acids, antioxidant activity.

\section{References}

1. Maksimov O.B., Rebachuk N.M., Boguslavskaja L.B. Rastitel'nye resursy, 1985, vol. 21, no. 2, pp. 216-220. (in Russ.).

2. Masaki H. Biol. Pharm. Bull, 1995, vol. 18, pp. 162-166.

3. Rice-Evans C.A., Miller N.J., Bolwell P.G., Bramley P.M., Pridh J.B. Free Radical Res., 1995, vol. 22, pp. $375-383$.

4. Afanas'ev I.B., Dorozhko A.I., Brodskii A.V., Kostyuk V.A., Potapovitch A.I. Z. Biochem. Pharmacol, 1989, vol. 38, pp. 1763-1769.

5. Melidou M., Riganakos K., Galaris D. Free Radic. Biol. Med., 2005, vol. 39, pp. 1591-1600.

6. Hoshino N., Kimura T., Yamaji A., Ando T. Free Radic. Biol. Med., 1999, vol. 27, pp. 1245-1250.

7. Smith A.H., Imlay J.A., Mackie R.I. Appl. Environ. Microbiol., 2003, vol. 69, pp. 3406-3411.

8. Kahkonen M., Hopia A.I., Vuorela H.J., Rauha J.P., Pihlaja K., Kuiaia T.S., Heinonen M. J. Agric. Food Chem., 1999, vol. 47(10), pp. 3954-3962.

9. Ghasemzadeh A., Jaafar H., Rahmat A. Molecules, 2010, vol. 15, pp. 4324-4333.

10. Strack D., Vogt T., Schliemann W. Phytochemistry, 2003, vol. 62, pp. 247-269.

11. Kujala T.S., Loponen J.M., Klika K.D., Pihlaja K. J. Agric. Food Chem., 2000, vol. 48(11), pp. 5338-5342.

12. Kujala T.S.,Vienola M.S., Klika K.D., Loponen J.M., Pihlaja K. Eur Food Technol., 2002, vol. 214, pp. 505-510.

13. Akita T., Hina Y., Nishi T. Biosci. Biotechnol. Biochem., 2002, vol. 66(4), pp. 902-905.

14. Georgiev V.G., Weber J, Kneschke E-M., Denev P.N., Bley T., Pavlov A.I. Plant Foods Hum Nutr., 2010, vol. 65, pp. 105-111.

15. Saljaev R.K., Kuzevanov V.Ja., Haptagaev S.B., Kopytchuk V.N. Fiziologija rastenij. 1981, vol. 28, pp. 1295-1305. (in Russ.).

16. Zaprometov M.N. Osnovy biohimii fenol'nyh soedinenij. [Fundamentals of Biochemistry of phenolic compounds]. Moscow, 1974, 214 p. (in Russ.).

17. Prohazka Zh. Hromatografija na bumage. Moscow, 1962, pp. 301-333. (in Russ.).

18. Georgiev V.G., Weber J, Kneschke E-M., Denev P.N., Bley T., Pavlov A.I. Plant Foods Hum Nutr., 2010, vol. 65. no. 2, pp. $105-111$.

19. Pavlov A., Kovatcheva P., Georgiev V., Koleva I., Ilieva M. Z. Naturforsch C. 2002, vol. 57, no. 7/8, pp. 640-644.

20. Maksimov O.B., Rebachuk N.M., Boguslavskaja L.B. Rastitel'nye resursy. 1985, vol. 21, no. 2, pp. 216-220. (in Russ.).

21. Kozarenko T.D. Ionoobmennaja hromatografija aminokislot. [Ion-exchange chromatography of amino acids]. Novosibirsk, 1975, 133 p. (in Russ.).

22. Lakin G.F. Biometrija. [Biometrics]. Moscow, 1990, 352 p. (in Russ.).

23. Shtarkman I.N., Gudkov S.V., Chernikov A.V., Bruskov V.I. Biohimija, 2008, vol. 73, no. 4, pp. 576-586. (in Russ.).

24. Aver'janov A.A., Lapikova V.P. Kislorodnye radikaly v himii, biologii $i$ medicine. Riga, 1988, pp. 203-222. (in Russ.).

25. Gandia-Ferrero F., Escribano J., Garcia-Carmona F. Planta, 2010, vol. 232, no. 2, pp. 449-460.

26. Pedreno M.A., Escribano J. J. Sci. Food Agric., 2001, vol. 81, no. 7, pp. 627-631.

27. Kujala T.S., Loponen J.M., Klika K.D., Pihlaja K. J.Agric.Food. Chem., 2001, vol. 48, no. 11, pp. 5338-5342.

Received December 25, 2013

Revised, March 6, 2014

\footnotetext{
* Corresponding author.
} 
